\title{
Functional Residual Capacity in Ventilated Infants and Children
}

\author{
YAKOV SIVAN, TIMOTHY W. DEAKERS, AND CHRISTOPHER J. L. NEWTH \\ Division of Pediatric Intensive Care, Children's Hospital of Los Angeles, University of Southern California \\ School of Medicine, Los Angeles, California 90027
}

\begin{abstract}
Positive end expiratory pressure (PEEP) is an accepted treatment for children with acute respiratory failure secondary to restrictive lung diseases. Using a simple technique based on open circuit nitrogen washout, we determined the functional residual capacity (FRC) in 25 ventilated children (age 3 wk-10 y) with acute respiratory failure secondary to restrictive lung disease (pulmonary edema, bilateral pneumonia). FRC measured at a physiologic level of PEEP $\left(2-4 \mathrm{~cm} \mathrm{H}_{2} \mathrm{O}\right)$ was $45.0 \pm 3.6 \%$ (mean \pm SEM; range $12-80 \%$ ) lower than normal predicted values. At the PEEP level chosen clinically (4-10 $\mathrm{cm} \mathrm{H}_{2} \mathrm{O}$, mean $=6.0$ ), the $\mathrm{FRC}$ was below normal predicted values for nonintubated children by a mean of $31.8 \%$ (range $0-73 \%)(p=0.0001)$ and only seven patients $(28 \%)$ had FRC within $20 \%$ below predicted normal values. FRC normalized at PEEP levels of 6-18 $\mathrm{cm} \mathrm{H}_{2} \mathrm{O}$ (mean = 11.6), which was up to $200 \%$ above the clinically chosen PEEP level. In six children without lung disease who were ventilated at a PEEP level of $2-4 \mathrm{~cm} \mathrm{H}_{2} \mathrm{O}$, the FRC was within normal range in two, but significantly higher (by $45 \%$ ) in the other four. We conclude that FRC in ventilated children with acute restrictive lung disease is significantly lower than normal and the clinically chosen PEEP fails to normalize the FRC in most of the cases. (Pediatr Res 28: 451454,1990 )
\end{abstract}

\section{Abbreviations}

PEEP, positive end expiratory pressure

ARF, acute respiratory failure

FRC, functional residual capacity

$\mathrm{FiO}_{2}$, fraction of inspired oxygen

PEEP is an accepted treatment for patients with ARF secondary to restrictive lung diseases. Its effectiveness is due to increasing the FRC, which represents recruitment of otherwise closed terminal airspaces and prevention of alveolar collapse. PEEP thereby decreases ventilation-perfusion mismatching and intrapulmonary shunting. These effects result in improved oxygenation (1-3). Normalization of FRC has been suggested as a method for PEEP titration $(4,5)$, especially when invasive hemodynamic measurements for systemic oxygen transport are not being used-a common situation in ventilated children. On the other hand, a high level of PEEP may increase FRC above normal, thereby overdistending alveoli and decreasing compliance.

Received July 31, 1989; accepted May 31, 1990.

Correspondence: Yakov Sivan, M.D., Pediatric Intensive Care Unit, Beilinson Medical Center, Petah-Tikva 49100, Israel.

Reprint requests: Christopher J. L. Newth, M.B., F.R.C.P.(C.), Pediatric ICU Administration, Childrens Hospital of Los Angeles, 4650 Sunset Boulevard, Los Angeles, CA 90027.
Excessive PEEP may also be associated with barotrauma and decreased cardiac output.

Although restoring FRC to normal levels may prove beneficial for ventilated children in respiratory failure, information on FRC is usually not available to the clinician because its bedside measurement has been impractical due to technical limitations. There are no data on "normal" FRC values in ventilated children without lung disease when a presumed "physiologic" level of PEEP (2-4 $\mathrm{cm} \mathrm{H}_{2} \mathrm{O}$ ) is applied; neither is there information on FRC in ventilated children with ARF. The only information presently available is from studies in adults (2), prematurely born infants with respiratory distress syndrome (6), and animal models (7).

In this study, we determined FRC in ventilated infants and children with acute respiratory failure using a newly developed bedside technique (8). The purpose of the study was to compare FRC results in this group with data from both intubated and nonintubated groups of infants and children with normal lungs. We also wanted to assess the extent by which conventional clinical methods of PEEP adjustment result in normalization of FRC.

\section{MATERIALS AND METHODS}

Fifteen children with pulmonary edema and 10 children with bilateral diffuse pneumonia requiring mechanical ventilation for $\mathrm{ARF}$ were studied. Their ages ranged from $3 \mathrm{wk}$ to $10 \mathrm{y}$ (mean $45 \mathrm{mo}$ ). Six children with normal lungs requiring mechanical ventilation for CNS diseases that did not affect the respiratory system were also studied (age 20 mo- 8 y).

All children in this study had a cuffed endotracheal tube and were ventilated using either a Siemens Servo 900C (Stockholm, Sweden) or a Sechrist constant flow ventilator (IV-100-B, Anaheim, $\mathrm{CA}$ ) at $\mathrm{FiO}_{2}$ less than 1.0.

FRC was measured by a newly developed automated technique based on the open circuit $\mathrm{N}_{2}$ washout (8). This technique is a bedside procedure developed specifically for ventilated infants and children and has been shown to be both accurate and very reproducible. In brief, the system consists of a second ventilator that has the same settings as the patient's ventilator but delivers $100 \% \mathrm{O}_{2}$ (Fig. 1). Both ventilators are connected to the proximal end of the endotracheal tube through a slider valve that activates at FRC, when the patient is switched to the washout ventilator. The gas leaving the second ventilator via the exhalation port (where a background flow of $100 \% \mathrm{O}_{2}$ is added) passes through a mixing chamber and the $\mathrm{N}_{2}$ concentration is then analyzed continuously by a respiratory mass spectrometer (Airspec MGA 2200 , Kent, UK), which also measures the minute volume of ventilation by the argon dilution technique (9). A computerbased data acquisition system (Sensormedics 2600 Pediatric Pulmonary System, Yorba Linda, CA) in line with the mass spectrometer integrates the $\mathrm{N}_{2}$ concentration signal electronically and provides a real time display of the $\mathrm{N}_{2}$ concentration $\left(\mathrm{N}_{2}\right.$ washout curve) on the monitor. The computer also controls the slider 


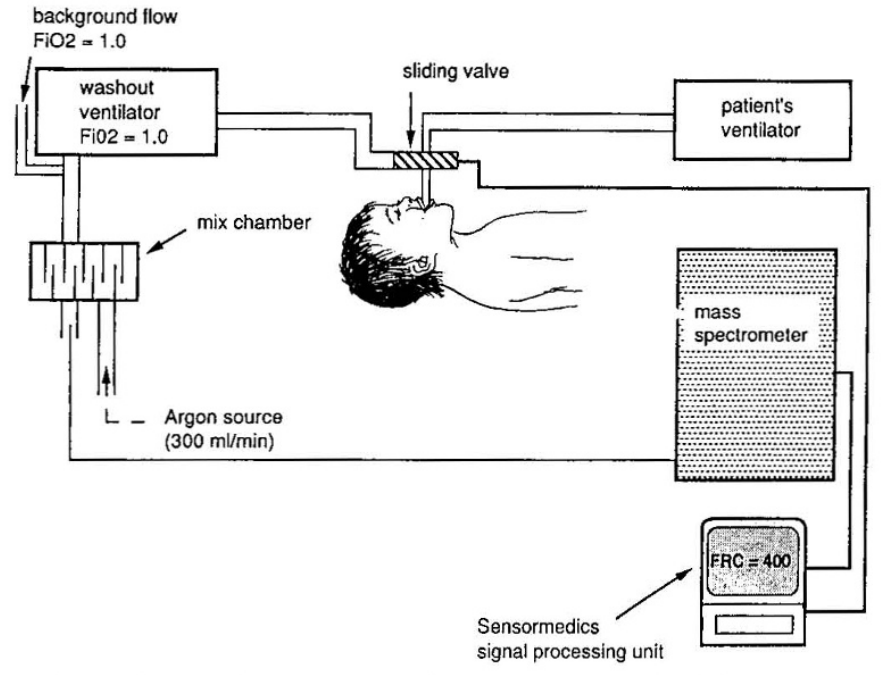

Fig. 1. System for FRC determination in ventilated children.

valve and automatically calculates the FRC at the end of the washout period according to the patient's alveolar $\mathrm{N}_{2}$ concentration measured before the study. Whenever the minute ventilation of the patient during the test was different from that used during calibration, a correction factor was applied (minute ventilation during test divided by minute ventilation during calibration). The system was calibrated by a syringe filled with krown amounts of room air attached to the slider valve. During the test, the washout period continued until alveolar $\mathrm{N}_{2}$ concentration dropped to zero (usually $40-60 \mathrm{~s}$ ). Whenever the continuous flow on the Sechrist ventilator was relatively high with respect to the absolute amount of $\mathrm{N}_{2}$ washed out (resulting from low patient minute volume of ventilation, high patient $\mathrm{FiO}_{2}$, or very low FRC), the $\mathrm{N}_{2}$ concentration signal was very small because a small amount of $\mathrm{N}_{2}$ was being mixed with a large amount of washout gas. In that situation, a splitter isolation valve (model no. 8890 , Boehringer Laboratories, Wynnewood, PA) was placed at the endotracheal tube end, which directed only the gas exhaled from the patient to the mixing chamber (8).

The $\mathrm{FiO}_{2}(0.35-0.65)$, background flow $(2-4 \mathrm{~L} / \mathrm{min})$, flow rate through the mixing chamber $(7-18 \mathrm{~L} / \mathrm{min})$, and FRC in this study were within the ranges tested in the validation of the method (8).

In each patient, FRC measurements were performed at $2-\mathrm{cm}$ $\mathrm{H}_{2} \mathrm{O}$ increments from a PEEP of $0 \mathrm{~cm} \mathrm{H}_{2} \mathrm{O}$ to the PEEP level at which the predicted normal FRC was achieved or a PEEP of 18 $\mathrm{cm} \mathrm{H} \mathrm{H}_{2} \mathrm{O}$ (whichever occurred first). Two to four repeated measurements were done at each level of PEEP and the mean was calculated. An interval of 3-5 min was allowed between each measurement.

All measurements were obtained when the patient was in the supine position. Measured FRC values were compared with predicted normal values for height, weight, and sex according to the appropriate age group (10-13). Whenever normal predicted values were available only for children in the sitting position, the predicted values were adjusted to $70-75 \%$ (we chose $72.5 \%$ ) of the normal predicted values for the sitting position (13-15). The overall predicted range of normal values for FRC was 17.1 $25.2 \mathrm{~mL} / \mathrm{kg}$ (mean \pm SEM $21.3 \pm 0.8 \mathrm{~mL} / \mathrm{kg}$ ).

The study was approved by the Committee of Clinical Research of our institution and informed consent was obtained on behalf of the patients in this study. The patient population for this study was not the same as the patient population for our first study in which the technique was developed and evaluated (8).

\section{RESULTS}

Patients with ARF due to restrictive lung disease had PEEP levels that ranged from 4 to $10 \mathrm{~cm} \mathrm{H}_{2} \mathrm{O}$ (mean $\pm \mathrm{SD} 6.0 \pm 2.0$ $\mathrm{cm} \mathrm{H}_{2} \mathrm{O}$; SEM 0.4). The ventilator settings and blood gas results are presented in Table 1. FRC measured at physiologic PEEP was $4.7-19.8 \mathrm{~mL} / \mathrm{kg}$ (mean $\pm \mathrm{SEM} 11.9 \pm 0.7 \mathrm{~mL} / \mathrm{kg})$, i.e. $12-$ $80 \%$ (mean \pm SEM $45.0 \pm 3.6 \%$ ) lower than normal predicted FRC values $(p<0.0001$, paired $t$ test) (Fig. 2). FRC measured at the clinically chosen PEEP level was $6.2-22.5 \mathrm{~mL} / \mathrm{kg}$ (mean $\pm \mathrm{SEM} 14.4 \pm 0.8 \mathrm{~mL} / \mathrm{kg}$ ), i.e. below normal predicted values by $0-73 \%$ (mean \pm SEM $31.8 \pm 3.9 \%$ ) using the formula: 100 $\times$ (predicted FRC - measured FRC)/predicted FRC $(p=0.0001$, paired $t$ test) (Fig. 3). Seven (28\%) of the children and infants had an FRC within $20 \%$ below the predicted normal value. Four (i.e. $16 \%$ of the total) were within $10 \%$ below the predicted normal value. The PEEP level at which FRC normalized ranged from 6 to $18 \mathrm{~cm} \mathrm{H}_{2} \mathrm{O}$ (mean $11.6 \mathrm{~cm} \mathrm{H}_{2} \mathrm{O}$, SEM 0.8). This PEEP level was higher $\left(p=0.0001\right.$, paired $t$ test) by $0-12 \mathrm{~cm} \mathrm{H}_{2} \mathrm{O}$ (mean $5.5 \mathrm{~cm} \mathrm{H}_{2} \mathrm{O}$ ) than the clinically chosen PEEP level (i.e. 0-200\% higher; mean 104\%) (Fig. 4).

In the six patients without lung disease, the PEEP administered was $2-4 \mathrm{~cm} \mathrm{H}_{2} \mathrm{O}$ (i.e. physiologic PEEP). In two of these patients, the measured FRC was close to the predicted normal values $(0$ and $11 \%$ higher than predicted, respectively), and above normal in four $(67 \%)$ by a mean of $45 \%$ (range $39-52 \%$ ). In the latter, FRC normalized only when PEEP was reduced to zero.

\section{DISCUSSION}

PEEP is an accepted therapy in children with ARF that is directed toward increasing FRC and, therefore, improving gas exchange (16). It is most useful in lung diseases that involve significant volume loss, i.e. pulmonary edema, adult respiratory distress syndrome, and diffuse bilateral pneumonia. In these cases, it is presumed that PEEP returns FRC toward normal. Individual FRC determination has been suggested as an integral part of the treatment of ventilated infants and children (17). Several methods have been suggested for optimal PEEP titration based on hemodynamic and respiratory variables $(1,2,4,5,16$, 18-20), but there is controversy about which technique is best. These methods are, however, invasive and are not routinely applied to children. One of the methods suggested for PEEP titration is the normalization of $\operatorname{FRC}(1,2,4,5,18,21)$. This also helps in lowering $\mathrm{FiO}_{2}$, and may aid recovery by reversing the pathophysiology of the disease $(22,23)$. Optimal mechanics of the edematous lung are obtained in the PEEP range where end expiratory lung volume (FRC) is returned to normal (24). Clinicians have not been able to use this technique routinely because FRC measurements have been technically impractical in the past in ventilated infants and children on a routine and continual basis.

The empirical application of PEEP in ARF due to restrictive lung disease based only on clinical judgement may underestimate the volume loss of the lungs caused by the disease process, or result in the use of excessive PEEP to a point where detrimental effects on cardiac output may occur. The use of excessive PEEP may also overdistend the lungs, causing the end expiratory lung volume to be above the normal FRC, resulting in compromised lung mechanics (24).

In our study, we investigated the effectiveness of using clinically chosen PEEP to normalize FRC. In all patients with ARF, at the clinically chosen level of PEEP, FRC was below predicted values. Only $28 \%$ of the patients had their FRC within an acceptable $\pm 20 \%$ range of the predicted normal values for age and weight. All were below the predicted FRC and in none was "overtreatment" with PEEP found. Clinical judgement (at least in our pediatric intensive care unit) appeared to underestimate significantly the amount of PEEP needed to return FRC to normal in ARF even when a PEEP of $10 \mathrm{~cm} \mathrm{H} \mathrm{H}_{2} \mathrm{O}$ was applied. Reasons for this underestimation include the concern of the clinician about the harmful effects of high PEEP, especially on lung mechanics, barotrauma, and cardiac output. The effect on the latter is unpredictable in children and requires invasive 
Table 1. Respiratory status of patients with $(1-25)$ and without $(A-F)$ restrictive lung disease*

\begin{tabular}{|c|c|c|c|c|c|c|c|c|c|c|c|}
\hline Patient & Ventilator & Mode & $\mathrm{FiO}_{2}$ & $\begin{array}{c}\text { Rate } \\
\text { breaths/ } \\
\text { min }\end{array}$ & $\begin{array}{c}\text { PEEP } \\
\left(\mathrm{cm} \mathrm{H} \mathrm{H}_{2} \mathrm{O}\right) \\
\end{array}$ & $\begin{array}{c}\text { PIP } \\
\left(\mathrm{cm} \mathrm{H} \mathrm{H}_{2} \mathrm{O}\right)\end{array}$ & $\begin{array}{c}\mathrm{V}_{\mathrm{T}} \\
(\mathrm{mL} / \mathrm{kg})\end{array}$ & $\mathrm{pH}$ & $\begin{array}{c}\mathrm{PaCO}_{2} \\
(\mathrm{~mm} \mathrm{Hg}) \\
\end{array}$ & $\begin{array}{c}\mathrm{PaO}_{2} \\
(\mathrm{~mm} \mathrm{Hg})\end{array}$ & Paralysis \\
\hline I & C & TC-P & 0.40 & 15 & 4 & 24 & & 7.37 & 38 & 95 & no \\
\hline 2 & C & TC-P & 0.35 & 25 & 8 & 22 & & & & & no \\
\hline 3 & $\mathrm{~S}$ & SIMV & 0.35 & 20 & 4 & & 10 & 7.53 & 36 & 118 & no \\
\hline 4 & S & $\mathrm{PC}$ & 0.50 & 20 & 4 & 28 & & 7.36 & 48 & 134 & no \\
\hline 5 & S & SIMV & 0.35 & 8 & 10 & & 12 & 7.47 & 40 & 110 & no \\
\hline 6 & S & SIMV & 0.38 & 10 & 6 & & 10 & 7.34 & 59 & 117 & no \\
\hline 7 & S & $\mathrm{PC}$ & 0.60 & 20 & 6 & 36 & & 7.42 & 40 & 71 & yes \\
\hline 8 & $\mathrm{C}$ & TC-P & 0.30 & 10 & 8 & 30 & & 7.40 & 40 & 80 & no \\
\hline 9 & $\mathrm{~S}$ & $\mathrm{PC}$ & 0.45 & 15 & 10 & 32 & & 7.47 & 42 & 87 & no \\
\hline 10 & C & TC-P & 0.50 & 16 & 10 & 34 & & 7.38 & 41 & 56 & no \\
\hline 11 & $\mathrm{~S}$ & $\mathrm{PC}$ & 0.65 & 25 & 6 & 44 & & 7.48 & 46 & 98 & yes \\
\hline 12 & $S$ & $\mathrm{PC}$ & 0.60 & 22 & 6 & 40 & & 7.42 & 27 & 80 & yes \\
\hline 13 & $\mathrm{~S}$ & $\mathrm{PC}$ & 0.62 & 15 & 6 & 34 & & 7.36 & 42 & 130 & no \\
\hline 14 & $\mathrm{~S}$ & $\mathrm{PC}$ & 0.57 & 25 & 5 & 32 & & 7.45 & 33 & 98 & yes \\
\hline 15 & S & SIMV & 0.38 & 15 & 6 & & 10 & 7.39 & 41 & 121 & no \\
\hline 16 & S & SIMV & 0.42 & 15 & 6 & & 10 & 7.58 & 30 & 97 & no \\
\hline 17 & S & SIMV & 0.45 & 25 & 8 & & 10 & 7.41 & 49 & 136 & no \\
\hline 18 & S & SIMV & 0.35 & 15 & 4 & & 10 & 7.41 & 35 & 85 & no \\
\hline 19 & S & SIMV & 0.40 & 15 & 6 & & 10 & 7.49 & 32 & 101 & no \\
\hline 20 & $\mathrm{~S}$ & PC & 0.61 & 40 & 6 & 40 & & 7.30 & 36 & 90 & no \\
\hline 21 & C & TC-P & 0.36 & 10 & 6 & 22 & & 7.41 & 36 & 89 & no \\
\hline 22 & S & SIMV & 0.45 & 20 & 4 & & 10 & 7.45 & 35 & 57 & no \\
\hline 23 & S & PC & 0.65 & 40 & 4 & 38 & & 7.32 & 52 & 88 & yes \\
\hline 24 & S & SIMV & 0.38 & 8 & 4 & & 10 & 7.47 & 35 & 107 & no \\
\hline 25 & C & TC-P & 0.35 & 20 & 4 & 22 & & & & & no \\
\hline A & C & TC-P & 0.35 & 20 & 4 & 20 & & & & & no \\
\hline B & $\mathrm{S}$ & SIMV & 0.28 & 16 & 2 & & 10 & 7.53 & 27 & 200 & no \\
\hline C & $\mathrm{S}$ & SIMV & 0.30 & 25 & 4 & & 10 & 7.47 & 40 & 140 & no \\
\hline D & C & TC-P & 0.28 & 20 & 4 & 20 & & 7.39 & 24 & 177 & no \\
\hline E & $\mathrm{S}$ & SIMV & 0.30 & 16 & 4 & & 10 & 7.42 & 46 & 129 & no \\
\hline $\mathrm{F}$ & S & SIMV & 0.23 & 14 & 4 & & 10 & & & & no \\
\hline
\end{tabular}

* Abbreviations: PIP, peak inspiratory pressure; $\mathrm{V}_{\mathrm{T}}$, tidal volume; $\mathrm{PaCO}_{2}$, arterial $\mathrm{CO}_{2}$ pressure; $\mathrm{PaO}_{2}$, arterial $\mathrm{O}_{2}$ pressure; $\mathrm{C}$, Sechrist; $\mathrm{S}$, Siemens Servo 900C: TC-P, time cycled pressure preset with continuous flow; SIMV, synchronized intermittent mandatory ventilation: PC, pressure control.

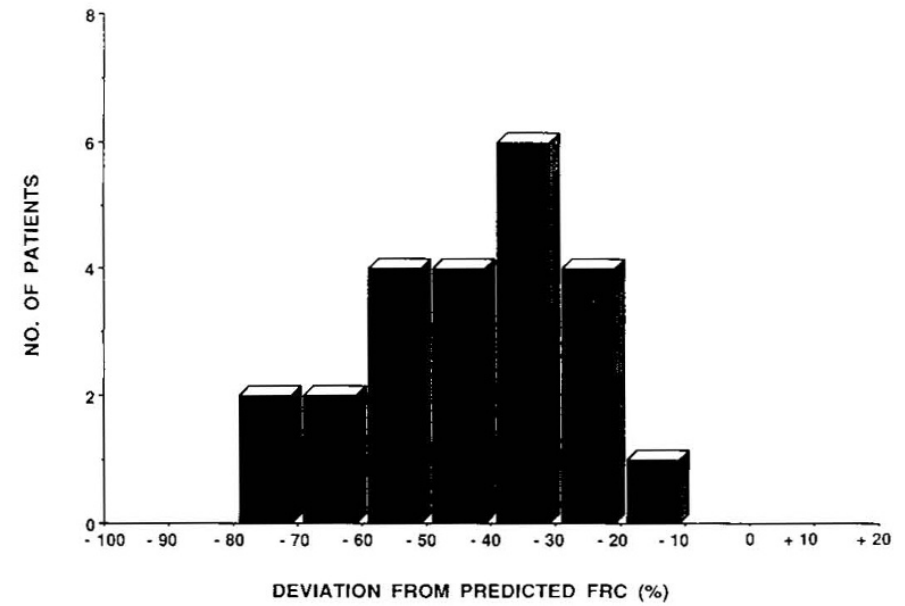

Fig. 2. Percent deviation from predicted FRC at physiologic PEEP level $\left(2-4 \mathrm{~cm} \mathrm{H}_{2} \mathrm{O}\right)$ in acute restrictive lung disease.

monitoring techniques for assessment. However, it can be easily controlled with intravascular volume expansion and cardiac inotropic drugs $(18,21,25)$. The former concerns of barotrauma and worsening lung mechanics due to overdistention are less justified according to our results and also those of Richardson $e t$ al. (6), who also measured FRC in a group of ventilated preterm infants with neonatal respiratory distress syndrome and found that in only a minority $(20 \%)$ of the patients was the FRC within $1 \mathrm{SD}$ of the normal range. In that series, the mean PEEP level was low $\left(4.4 \mathrm{~cm} \mathrm{H}_{2} \mathrm{O}\right)$, and in about $20 \%$ of the patients who had only minimal lung disease the FRC was above normal.

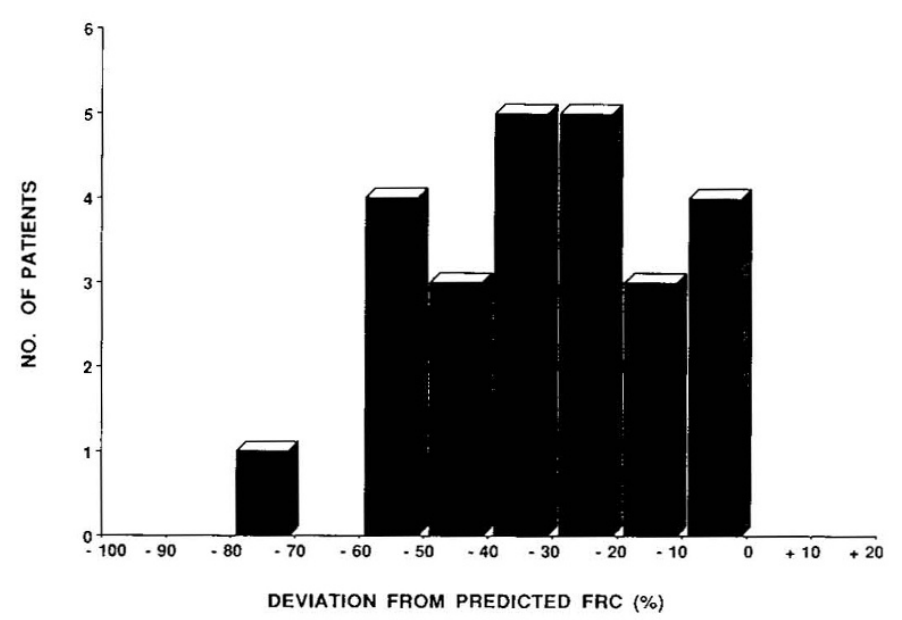

Fig. 3. Percent deviation from predicted FRC at clinically chosen PEEP level in patients with acute restrictive lung disease.

When comparing the measured FRC values with predicted normal values, we used data from nonventilated children because normal data for ventilated children do not exist. The published normal data for FRC in small children were mostly obtained using methods different from ours. We preferred the values of Gerhardt et al. (12) because they were obtained by the same $\mathrm{N}_{2}$ washout technique. However, because their normal values were obtained mainly in infants under $2 \mathrm{y}$ of age with only a small sample for the 2-5 y age range, we used also other references: Taussig et al. (13) for children under 6 y; and Polgar 


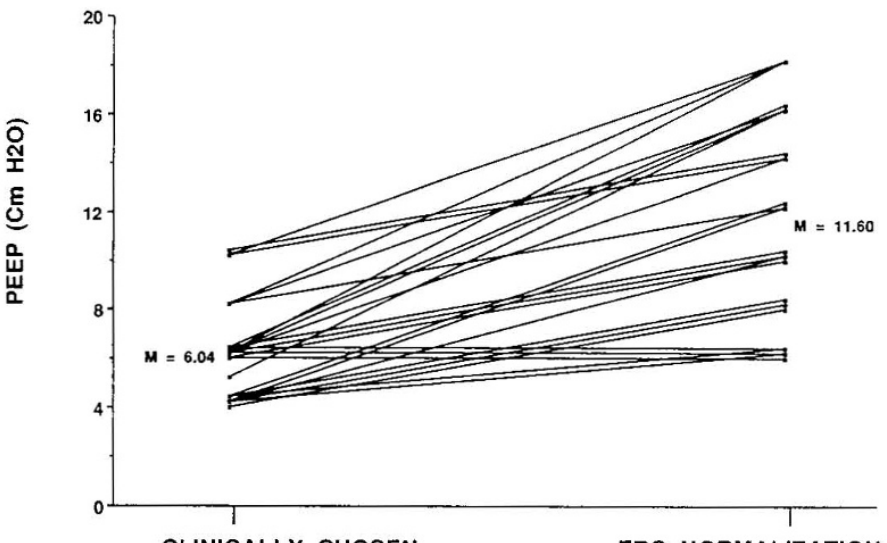

CLINICALLY' CHOSEN

FRC NORMALIZATION

Fig. 4. The change in PEEP level between the clinically chosen PEEP and PEEP of FRC normalization in acute restrictive lung disease ( $p=0.0001$, paired $t$ test).

and Promadhat (10) and Zapletal (11) for children over 6 y. These references used the helium dilution technique to measure FRC. However, because the data obtained by Taussig et al. (13) for children over 3 y of age and the data from Polgar and Promadhat (10) and Zapletal (11) were obtained in the sitting position, we adjusted those normal values to supine body position according to the finding that supine FRC is lower than sitting FRC by $25-30 \%$ in healthy children (13-15) (we chose $27.5 \mathrm{~mL} / \mathrm{kg}$ ). Compared to these references, the FRC in our patients with normal lungs were at or above normal predicted values for age, implying that the low FRC in the patient with respiratory failure could not be attributed to body position. It has been suggested that PEEP is required to maintain FRC in newborn infants (26). The data presented by Berman et al. (26) show that for term and preterm infants recovering from restrictive lung diseases, FRC at physiologic PEEP was $32 \mathrm{~mL} / \mathrm{kg}$ (by helium dilution). Other studies using the helium dilution technique showed lower results for normal newborn infants: Ronchetti et al. (27), $20.5 \mathrm{~mL} / \mathrm{kg}$; and Taussig et al. (13), 15.2-23.7, $\mathrm{mL} / \mathrm{kg}$. It is hard to explain Berman et al.'s finding (26) that FRC at physiologic PEEP was higher in patients with lung disease. In comparison, Gerhardt et al., (12) using an open circuit $\mathrm{N}_{2}$ washout technique similar to ours, found the FRC to be 16.2 $\mathrm{mL} / \mathrm{kg}$ for newborns. It could be that the sick patients in the Berman et al. study were tachypneic post extubation. Thus, inspiration started before the patients were back to FRC, resulting in air trapping.

The six patients with normal lungs in our study were 6-mo- to 8 -y-old. It may indeed be that the highly compliant chest wall in newborns and small infants requires PEEP to maintain FRC at this age group (FRC falls even further in these patients during rapid-eye-movement sleep), whereas in older patients the relatively rigid rib cage pulls the lung outward and maintains normal FRC. This explanation needs to be tested in a future study because physiologic PEEP in normal children has never been tested and is only assumed to be $2-4 \mathrm{~cm} \mathrm{H} \mathrm{H}_{2} \mathrm{O}$.

We conclude that conventional methods of PEEP selection for infants and children with acute restrictive lung disease in our pediatric intensive care unit rarely result in normalization of the FRC. We believe our practices in PEEP selection differ little from those in other pediatric intensive care units in North America. Because a wide variety of FRC values can be expected with the majority of these values below normal, individual determination of FRC at various PEEP levels should be pursued.

Acknowledgments. The authors thank L. Augustine, R.R.T., D. Clemens, R.R.T., and M. Scanlon for superb technical assistance.

\section{REFERENCES}

1. Suter PM, Schlobohm RM 1974 Determination of functional residual capacity during mechanical ventilation. Anesthesiology 41:605-607

2. Katz JA, Ozanne GM, Zinn SE, Fairley HB 1981 Time course and mechanisms of lung-volume increase with PEEP in acute pulmonary failure. Anesthesiology 54:9-16

3. Shapiro BA 1981 Airway pressure therapy for acute restrictive pulmonary pathology. In: Shoemaker WC, Thomson WL (eds) Critical Care. State of the Art, Vol. 2. Society of Critical Care Medicine, Fullerton, CA, pp 1-53

4. East TD, Adriano KP, Pace NL 1986 Computer-controlled optimization of positive end-expiratory pressure. Crit Care Med 14:792-797

5. East TD, Veen JCC, Pace NL, McJames S 1988 Functional residual capacity as a noninvasive indicator of optimal positive end-expiratory pressure. J Clin Monit 4:91-98

6. Richardson P, Bose CL, Calstrom JR 1986 The functional residual capacity of infants with respiratory distress syndrome. Acta Paediatr Scand 75:267-271

7. Layon J, Banner MJ, Jeager MJ, Peterson CV, Gallagher TJ, Modell JH 1986 Continuous positive airway pressure and expiratory positive airway pressure increase functional residual capacity equivalently. Chest 89:517-521

8. Sivan Y, Deakers T, Newth CJL 1990 An automated bedside method for measuring functional residual capacity by $\mathrm{N}_{2}$ washout in mechanically ventilated children. Pediatr Res 28:446-450

9. Davis NJH, Denison DM 1979 The measurement of metabolic gas exchange and minute volume by mass spectrometry alone. Respir Physiol 36:261-267

10. Polgar G, Promadhat V 1971 Pulmonary Function Testing in Children. Techniques and Standards. Saunders, Philadelphia, pp 100-116

11. Zapletal A 1987 Lung Function in Children and Adolescents. Methods, Reference Values. Karger, New York, pp 120-140

12. Gerhardt T, Reifenberg L, Hehre D, Feller R, Bancalari E 1986 Functional residual capacity in normal neonates and children up to 5 years of age determined by a $\mathrm{N}_{2}$ washout method. Pediatr Res 20:668-671

13. Taussig LM, Harris TR, Lebowitz MD 1977 Lung function in infants and children: functional residual capacity, tidal volume, respiratory rate. Am Rev Respir Dis 116:233-239

14. Guebelle F, Goffin C 1962 Respiratory studies in children. IV. Lung volumes and body positions in healthy children. Acta Paediatr 51:255-260

15. Blair E, Hickman JB 1955 The effect in change in body position on lung volume and intrapulmonary gas mixing in normal subjects. $\mathrm{J}$ Clin Invest 34:383-389

16. Nichols DG, Rogers MC 1987 Adult respiratory distress syndrome. In: Rogers MC (ed) Textbook of Pediatric Intensive Care. Williams \& Wilkins, Baltimore, pp 249-255

17. Shannon DC 1989 Rational monitoring of respiratory function during mechanical ventilation of infants and children. Intensive Care Med 15:S13-S16

18. Suter PM, Fairley HB, Isenberg M 1975 Optimum end-expiratory airway pressure in patients with acute pulmonary failure. N Engl J Med 292:284289

19. Kuckelt W, Scharfenberg J, Mrochen H, Dauberschmidt R, Petrakov G, Kassil W, Meyer M 1981 Effect of PEEP on gas exchange, pulmonary mechanics, and hemodynamics in adult respiratory distress syndrome (ARDS). Intensive Care Med 7:177-185

20. Witte MK, Galli SA, Chatburn RL, Blumer JL 1988 Optimal positive endexpiratory pressure therapy in infants and children with acute respiratory failure. Pediatr Res 24:217-221

21. Pollack MM, Fields AI, Holbrook PR 1980 Cardiopulmonary parameters during high PEEP in children. Crit Care Med 7:372-376

22. Kirby RR, Downs JB, Civetta JM, Modell JH, Dannemiller EJ, Klein EF, Hodges M 1975 High level positive end expiratory pressure (PEEP) in acute respiratory insufficiency. Chest 67:156-163

23. Gallagher TJ, Civetta JM, Kirby RR 1978 Terminology update: optimal PEEP. Crit Care Med 6:323-326

24. Richardson P, Carlstrom JR 1985 Effects of end-expiratory lung volume on lung mechanics in normal and edematous lungs. Respiration 47:90-97

25. Falke KJ, Pontoppidan H, Kumar A, Leith DE, Geffin B, Laver M 1972 Ventilation with end-expiratory pressure in acute lung disease. J Clin Invest 51:2315-2323

26. Berman LS, Fox WW, Raphaely RC, Downes JJ 1976 Optimum level of CPAP for tracheal extubation of newborn infants. J Pediatr 89:109-112

27. Ronchetti R, Senterre J, Geubelle F 1971 Functional residual capacity and distribution of inspired air in the premature baby: preliminary results. Acta Paediatr Belg 25:5-16 